\title{
Strategic Information Systems Planning: An Empirical Evaluation of Its Dimensions
}

\author{
Carla L.Wilkin', Narciso Cerpa ${ }^{2}$
}

\begin{abstract}
Strategic management of Information Technology (IT) has long been regarded as a critical component of business performance. This study addresses two objectives. Firstly we investigate the practice and effectiveness of Strategic Information Systems Planning (SISP) as a function of strategic management in 29 large Australian organizations. Secondly we review these results through a theoretical lens established by Segars et al. (1998) who identified six dimensions that provide a structured approach to reviewing the SISP process. Our results show that SISP was widely used in these 29 organizations in aspects such as planning associated with strategic IS investment and application, and whilst the theoretical review generally supported the literature, some amendments are required to the participation and focus dimensions suggested by Segars et al. (1998). Such results have implications for both practitioners and researchers.
\end{abstract}

Keywords: strategic information systems planning (SISP); strategic management of IT; corporate planning.

'Department of Accounting and Finance, Faculty of Business and Economics. Monash University. PO Box 197, Caulfield East. Victoria 3 145, Australia. Email: carla.wilkin@monash.edu Ph: +6I 39903 I438

2Department of Computer Science, Faculty of Engineering, Universidad de Talca, Chile. Email: ncerpa@utalca.cl Ph: 56-75-20I7I0

ISSN: 07 I8-2724. (http://www.jotmi.org)

Journal of Technology Management \& Innovation (C) Universidad Alberto Hurtado, Facultad de Economía y Negocios. 


\section{Introduction}

Strategic planning for Information Technology (IT) is increasingly regarded as both a key component of corporate planning and a critical focus area for sound governance of IT.Accordingly it has become a concern for both academics and practitioners (Wilkin and Chenhall, 20I0). For practitioners the primary concern is ensuring that IT positively and effectively supports and is supported by corporate strategic objectives, so it provides the necessary capability to deliver business value. This is reflected in IT strategy being identified as a top issue for American firms (Peak et al., 2005) and as a Critical Success Factor (Read, 2004). The benefit of achieving strategic fit is that it should ensure that IT is positioned to assist in adding value to products and/or services, which in turn assists with competitive position and management efficiency through cost control and more accurate reporting.

Similarly, in an academic context, prior research into strategic planning of IT supports the need to ensure fit between IT and business strategy (Tallon, 2007/2008), and delineation of key IT capabilities, future IT requirements and operational IT resourcing (people and assets) in order to meet business needs (Schwarz and Hirschheim, 2003; Bernroider, 2008). Herein researchers have demonstrated a need to focus on organizational goals to ensure IT supports individual strategic processes (Tallon, 2007/2008). Typically this is achieved by acquiring a shared understanding between IT and business leadership, and connecting business and IT planning (Reich and Benbasat, 2000). Related research has shown the need for planning to produce strategies that can be dynamic, shared and reshaped to meet changing landscapes (Coutaz, 2005; Grover and Segars, 2005; Kim and Mauborgne, 1999), with contemporary environments needing, at times, innovative strategies to produce long-term growth (Kim and Mauborgne, 1999) and strategic flexibility (Eisenhardt, 2002).

Whilst this shows consensus between practitioners and academics about the desired results from IT strategic planning, what is not as clear are the key indicators of an effective Strategic Information Systems Planning (SISP) process. Although indicators like ROI can be indicative, evidence of effective outcomes can be hard to extrapolate from the myriad of related business initiatives. Therefore, the first objective of this study was to investigate the practice and effectiveness of SISP, as a function of strategic management, in 29 large Australian organizations. Using in depth interviews with key stakeholders including IT directors, CIOs and/or those charged with the organizational responsibility for such decision-making, we demonstrated that organizations did see value in SISP, as evidenced by its well established use, with results from SISP being managed as a corporate rather than IT function. But evaluation of the process by which it is instituted is less well defined. Consequently, our second objective in this study was to review these results through the theoretical lens established by Segars et al. (1998) concerning a structured approach to reviewing SISP. Comprizing six dimensions, namely comprehensiveness, formalization, focus, flow, participation and consistency, this lens provided a "sound foundation for structuring dialog" regarding the SISP process (Segars et al., 1998:17). Such investigation enabled more abstract evaluation of the reportedly successful SISP practices. Results revealed new insights into areas where organizations could improve their SISP processes; and equally revealed a need to extend the understanding of two dimensions in order to reflect the evolving role of IT in organizations.

The remainder of the paper is structured as follows: after the literature review, which explores SISP, its role in corporate strategic management, and Segars et al. (1998) six dimensions in the SISP process, we outline the methodology, which includes an overview of the research approach and the data collection and data analysis processes. We then present the results and discussion before concluding the paper.

\section{Literature Review}

\section{a) SISP and its Role in Corporate Strategic Management}

Strategic IT management is one of the most demanding and critical tasks for organizational performance. By identifying IT capabilities and ensuring integration between business and IT functionality (Schwarz and Hirschheim, 2003), it aims to achieve better business outcomes through better IT performance (ITGI, 2009). Despite evidence that firms with effective IT strategic management have $20 \%$ higher profits, with success related to effective allocation of IT resources (Weill and Ross, 2005), some organizations are yet to be convinced of the need. This poor track record from IT investment is revealed in surveys that consistently show "20 to 70 percent of large-scale investments in IT-enabled change are wasted, challenged or fail to bring a return to the enterprise" (Val IT, 2008:7). Likewise, The Standish Group (2004) found a success rate of $2 \%$ for IT projects over $\$ 10$ million dollars, with no discernible improvement in IT failure rates since 1994; a Fortune 1000 survey found that $\mathrm{ClOs}$ believed 40 percent of all IT spending brought no return (Watters, 2004); and an ITGI survey (2009) of CEO's found $75 \%$ believed there were barriers that prevent full returns from IT investments. Given this it is not surprising that a recent study into IT governance for Enterprise Resource Planning (ERP) found that only about $66 \%$ of organizations used strategic understanding to inform their decisions about ERP systems (Bernroider, 2008). 
Yet, as highlighted by King (1978), the importance of a more deliberate approach to strategic IT management is well established; with the discussion extended by researchers including Galliers (1991) and more formally established as a concept by Lederer and Sethi (1988). Herein Galliers (1991) presaged strategic management for IT as having: a strategy comprizing maintenance of comparative strategic advantage; a structure of centrally co-ordinated coalitions; interorganizational systems with information system (IS)-based products and external/internal data integration; IS influence at the Board level; IS staff functioning as a business team; senior management understanding IS and its potential; and interactive planning. Further he, like McKersie and Walton (1991), stressed that IS strategy had to incorporate change management as well as evaluation and review. SISP, with its concern for integrating investment and management of IS with organizational strategy, was particularly evaluated by researchers in the 1990s. Early problems with SISP related to a lack of management commitment and a lack of control mechanisms that ensured plans were followed (Lederer and Sethi, 1988, 1996). Similarly, Premkumar and King (1992) showed that significant relationships exist between two of the performance measures: planning effectiveness and IS's contribution to organizational performance, and "fit" between the role of IS and the quality of the planning process. Lederer and Sethi (1996) subsequently identified that SISP plays a significant role in ensuring IT contributes effectively to an organization: the challenge was that participants had problems with the process, particularly prioritizing where SISP delivered benefit to their organization; and problems with time management that included balancing the immediacy of demands for action against the need for comprehensive scoping of possibilities.

As IT has evolved from a focus on internal processes to a more strategic role, SISP has been used as "the process of deciding the objectives for organizational computing and identifying potential computer applications" (Lederer and Sethi, 1988:445) that "assist an organization in executing its business plans and realizing its business goals" (Lederer and Sethi, 1996:35). As a long established process for IT planning (Bechor, 2010; Holley et al., 2004), SISP is defined as:

"(I) supporting and influencing the strategic direction of the firm through identification of value-adding computerized information systems, (2) integrating and coordinating various organizational technologies through development of holistic information architectures, and (3) developing general strategies for successful systems implementation" (Segars et al., 1998:306).

Its foundations lie in findings that include the need for IT to be: conceptually evaluated; strategically aligned with business goals (King, 1988) not individual applications; top-down driven; an enabler of business/IT initiatives (Basu et al., 2002); and/or a facilitator of competitive advantage (Peter, 198I).
These are achieved through developments in architecture (primarily organizational) that facilitate data-sharing and technology integration (Segars et al., 1998).

Accordingly, because SISP requires organizations to define their business goals and plans, then determine IT strategies that optimize achieving business objectives (Cohen, 2008), it is broader and more corporately accountable than other forms of IS planning (Segars et al., 1998). Contextually the characteristics that define SISP include: scope (which is broad); perspective (which positions planning at the highest organizational levels); timeframe (which is longer as initiatives often relate to significant organizational change); and level of abstraction (as SISP relates to more conceptual planning than to practical initiatives). Therefore, SISP involves formalizing:

- the best strategic business/IT planning approaches for a particular organization;

- a strategic plan for implementation;

- how to champion the process;

- the size of commitment regarding people, financial and other resources; and

- a review processes.

\section{b) Segars Six Dimensions in the SISP Process}

Given the importance attributed to SISP in ensuring the strategic function of IT in an organization, our second objective involved reviewing the effectiveness of the SISP process. Herein, drawing upon a wide body of investigative research from the 1980s and 1990s, Segars et al. (1998:17) identified six dimensions (comprehensiveness; formalization; focus; flow; participation; and consistency) that provided a structured approach to reviewing the SISP process (see Table I).

Given the increasing sophistication of IT; the exponential growth in investment in IT; and the ever-changing contribution that IT can/does make to organizational performance, it is interesting that a constant in such a dynamic environment has been SISP.Thus, there is timely relevance for a fresh investigation like ours into how SISP is used and its success factors.

\section{Methodology}

\section{a) Research approach}

Our study involved carefully planned structured in-depth interviews with IT directors, $\mathrm{ClOs}$ and/or those charged with the responsibility of making such decisions in their organization. This approach enabled us to systematically gather rich descriptive information in order to understand the organizational approaches taken (Brown, 1999). To ensure 


\begin{tabular}{|c|c|}
\hline Dimension & Characteristics and meaning of the dimension \\
\hline Comprehensiveness & $\begin{array}{l}\text { This concerns "the extent to which an organization attempts to be ex- } \\
\text { haustive or inclusive in making and integrating strategic decisions" } \\
\text { (Fredrickson and Mitchell, 1984:402). It is widely regarded as the exten- } \\
\text { siveness of the search for solutions, which must be balanced against the } \\
\text { costs of time and financial resources (Segars et al., 1998; Lederer and } \\
\text { Sethi, 1996). }\end{array}$ \\
\hline Formalization & $\begin{array}{l}\text { This relates to "the existence of structures, techniques, written pro- } \\
\text { cedures, and policies that guide the planning process" (Segars et al., } \\
\text { 1998:305). Efficiency gains from collecting, storing and using informa- } \\
\text { tion in a highly structured manner enhance consideration of a wider } \\
\text { range of strategic issues. }\end{array}$ \\
\hline Focus & $\begin{array}{l}\text { This is evident through "the balance between creativity and control } \\
\text { orientations inherent within the strategic planning system" (Segars et al., } \\
\text { 1998:306). These orientations are commonly either innovative approach- } \\
\text { es to opportunities and threats; and/or integrative approaches linked to } \\
\text { control, as implemented through budgets, resource allocation, and asset } \\
\text { management. }\end{array}$ \\
\hline Flow & $\begin{array}{l}\text { This relates to the "locus of authority and devolution of responsibilities" } \\
\text { (Segars et al., 1998:306). For example, whether a top-down or bottom-up } \\
\text { approach is taken. }\end{array}$ \\
\hline Participation & $\begin{array}{l}\text { This is evident in the extent to which multiple functional areas and key } \\
\text { personnel at lower levels of the organization are involved; as well as the } \\
\text { extent of lateral communication in the process (Segars et al., 1998). }\end{array}$ \\
\hline Consistency & $\begin{array}{l}\text { This is determined by the frequency of planning activities and per- } \\
\text { formance evaluation. High levels of consistency are characterized by } \\
\text { frequent meetings, constant communication and reassessments of the } \\
\text { overall strategy, which are all valuable in a dynamic organizational envi- } \\
\text { ronment (Segars et al., 1998). }\end{array}$ \\
\hline
\end{tabular}

Table I: The six dimensions of the SISP process (as determined by Segars et al., 1998)

consistency we developed a detailed interview guide as described below (see Table 3). In a sense the interview guide acted as a questionnaire that was completed in the course of an interview.

The measures of SISP contained in the interview guide were developed using Churchill's (Churchill, 1979) framework.Although this framework is targeted at developing marketing constructs, it is applicable to a variety of studies in both strategic management and IS (Venkataraman and Grant, 1986). Given that many variables of interest are inherently complex in nature, we chose multi-item measures to overcome the difficulties of single measures having considerable uniqueness and thus low correlation with the attribute being meas- ured. This also avoided the issue of framing the concepts too narrowly as individual items could be averaged, leading to more robust conceptualizations, which reduced measurement error.

We commenced the process of developing measures by specifying the domain construct, which delineated what is/is not relevant to the research. The theoretical underpinnings were drawn from prior literature about planning system design dimensions and planning systems for SISP (Segars et al., 1998). Planning system design draws on strategic management practices (Kukalis, I99I): planning systems for SISP draws on conceptualizations of IT (Pyburn, 1983). By combining these two perspectives we developed measures that 
were consistent with the established designs for: planning comprehensiveness; formalization; focus; planning flow; participation; consistency; and planning effectiveness (Grover and Segars, 2005). Thus, our construct measures were based on the relevant literature including, where appropriate, the use of existing measurement scales and expert opinion (Cerpa and Verna, 1998). This ensured completeness and repeatability. Moreover, heeding implications for the findings and replicability of the study, we considered its construct validity, conclusion validity, external validity and criterion validity (see Table 2).

The result was a four-part interview guide comprizing a mix of unstructured, semi-structured and structured questions (see Table 3). The guide was pilot tested on a random group of organizations prior to its use in the main study.

The result was a four-part interview guide comprizing a mix of unstructured, semi-structured and structured questions (see Table 3). The guide was pilot tested on a random group of organizations prior to its use in the main study.

\section{b) Data collection}

Like previous studies (e.g. Segars et al., 1998) we collected empirical evidence from key personnel including $\mathrm{ClOs}$, IT Planning Managers, Directors of Information Services, and National IT Managers. Because not all organizations use SISP, our research design did not lend itself to scientific sampling techniques (Basu et al., 2002). Some organizations' IT was not sufficiently significant to warrant formal planning; others outsourced IT operations and development; and some stated SISP produced insufficient organizational benefits. Therefore, in line with prior explanatory studies of complex phenomena, we deployed a non-scientific sampling method that restricted data collection. This approach is justified provided care is taken in generalizing results (Basu et al., 2002; Porter and Millar, 1985).

\section{c) Data analysis}

As foreshadowed above, the interview guide comprized a mix of unstructured, semi-structured and structured questions requiring quantitative and qualitative responses. For example, management experience was provided in years and the number of people involved in corporate planning was similarly quantitative. Where a yes/no answer was required

\begin{tabular}{|c|c|}
\hline Validity measure & Meaning and operationalization \\
\hline $\begin{array}{l}\text { Construct } \\
\text { validity }\end{array}$ & $\begin{array}{l}\text { - Face construct validity was high as our measurement instrument appeared to contain } \\
\text { all of the "obvious" constructs considered by various experts. } \\
\text { - Content validity was high due to a detailed literature review, discussions with prac- } \\
\text { titioners and previous work on the topic. Thus, many of the critical factors that define } \\
\text { SISP were identified prior to development of the interview guide. To avoid guess work, } \\
\text { participants were asked to reflect on planning (both corporate and SISP) in their organi- } \\
\text { zations, but were left unaware of the research's main objective }\end{array}$ \\
\hline $\begin{array}{l}\text { Conclusion } \\
\text { validity }\end{array}$ & $\begin{array}{l}\text { - The measures were considered reliable as: } \\
\text { O they were based on a literature review; } \\
\bigcirc \text { all participants possessed sufficient experience to respond to the questions; and } \\
\bigcirc \text { guidance was provided within the instrument to ensure reliability and consistency. }\end{array}$ \\
\hline External validity & $\begin{array}{l}\text { - The key to establishing external validity is ensuring that the sample populations repre- } \\
\text { sent the general population to which the findings will be applied. } \\
\text { - Use of IT directors, CIOs and/or those charged with decision-making responsibilities } \\
\text { added credibility. } \\
\text { - Participants were recruited on the basis of convenience sampling (all located in one } \\
\text { Australian capital city), with the only incentive offered being a summary of the final } \\
\text { results. }\end{array}$ \\
\hline $\begin{array}{l}\text { Criterion valid- } \\
\text { ity (or predictive } \\
\text { validity) }\end{array}$ & $\begin{array}{l}\text { - This refers to the ability of our interview guide to accurately predict/portray the status } \\
\text { of SISP in organizations. } \\
\text { - All respondents have experience and involvement in planning in their organizations. }\end{array}$ \\
\hline
\end{tabular}

Table 2: Validity measures related to this study

ISSN: 07I 8-2724. (http://www.jotmi.org)

Journal of Technology Management \& Innovation (C) Universidad Alberto Hurtado, Facultad de Economía y Negocios. 


\begin{tabular}{|c|c|}
\hline $\begin{array}{l}\text { Structure of the interview } \\
\text { guide }\end{array}$ & Issues explored \\
\hline Parts 1 and 2: Demographics & $\begin{array}{l}\text { Respondents' details and experience. } \\
\text { - } \quad \text { Nature of their organization, including its size and that of their IS } \\
\text { department. }\end{array}$ \\
\hline $\begin{array}{l}\text { Part 3: Organization's ap- } \\
\text { proaches to corporate strate- } \\
\text { gic planning }\end{array}$ & $\begin{array}{l}\text { - } \quad \text { Use of formal corporate planning functions. } \\
\text { - } \quad \text { Involvement in this process. } \\
\text { - } \quad \text { Estimated annual costs. } \\
\text { - } \quad \text { Methods used to communicate corporate plans. } \\
\text { lower, or a combination. }\end{array}$ \\
\hline $\begin{array}{l}\text { Part 4: Issues pertaining to } \\
\text { SISP as used }\end{array}$ & $\begin{array}{l}\text { - } \\
\text { - } \\
\text { - } \\
\text { - }\end{array}$ \\
\hline
\end{tabular}

Table 3: Structure of the interview guide and issues explored.

(for example regarding the presence of a steering committee), results were coded as yes $=1$ and no $=2$. Similarly, results from the: Scope of IS Strategic Plan (Local I, Region 2, State 3, National 4, International 5); IS Strategic Planning Cycle (Half-yearly I, Annually 2, Bi-annually 3, and Other 4); and Frequency of meetings of the SISP Committee (I = $<$ Quarterly, $2=$ Quarterly, $3=$ Half yearly, $4=$ Annually, $5=$ $\mathrm{Bi}$-annually, $6=>\mathrm{Bi}$-annually) were all coded. In this manner we were able to deduce means and averages across both the whole group and later within clusters where there were perceptible variations that provided additional insights.

\section{Results}

Organizations involved in this study were generally mediumto-large in size from a range of industry sectors including: Manufacturing; Service; Finance; Insurance; Government; Media; IT; and Banking, with some being part of multi-national operations. For each organization data was collected about their approach to corporate strategic planning, including their mission, involvement and cycle time. Data related to SISP processes included: formality; scope; frequency; participants and processes involved; outputs; perceptions regarding success or effectiveness; technologies used; and other qualitative factors. In terms of scope, many (mainly in the Financial Services and Manufacturing sectors) had either a national $(37.9 \%)$ or an international $(37.9 \%)$ focus. State (I3.8\%) or local/regional focus ( $10.3 \%)$ was lower.
Those interviewed were involved in their organization's IS/IT planning component. In general they were highly experienced, having up to 35 years' IS experience, with the mean being 15.66 years. General management experience was somewhat lower (up to 20 years), with the mean being 8.65 years, although not all subjects indicated they had general management experience. Job titles like CIO, IT Planning Manager, Director of Information Services, and National IT Manager, implied seniority. This was important as previous studies suggested that senior personnel involved in IS planning could provide broader organizational perspectives of IS activities than department heads, a group previously criticized for more parochial views (Basu et al., 2002). Regarding organizational structure, the most common response revealed a mixture of centralization and decentralization (with product or service divisions).

The interview results indicated general consensus that SISP was a valuable tool for strategic planning and investment in IT. On average SISP had been used for 6 years, with 6 organizations using it in excess of 10 years and 5 less than 3 years. There was strong agreement $(79.3 \%)$ that IT provides competitive advantage and IT strategic goals were aligned with corporate goals (a factor that had improved over the past 5 years). The majority saw SISP as essential to organizational performance $(48.3 \%$ very essential $/ 24.1 \%$ crucially essential), although the effectiveness of SISP was slightly lower $(62.1 \%$ saw it as satisfactory). 
In terms of major benefits, enhances the competitive position of the organization $(79.3 \%$ ) came out as the top benefit, followed by quality of decisions arising from the process (72.4\%). The least perceived benefit was the need to do it to survive $(41.4 \%)$.

\section{Discussion}

Drawing on our results, which showed that the organizations sampled responded favourably regarding the effectiveness of their SISP processes and outcomes, our final step involved independently reviewing the data through the lens of Segars et al.'s (1998) already validated six dimensions for a successful SISP process. This revealed both strengths and deficiencies in the 29 organizations.

\section{Comprehensiveness}

- Organizations sought to achieve comprehensiveness by applying several processes or methodologies to their SISP activities in order to ensure coverage of organizational needs.

- Generally four methodologies were used by each to support their processes.

o Business Information Analysis and Integration Technique was the least used method (with $3.45 \%$ of organizations adopting it).

o Business Systems Planning was the most utilized (65.52\%: particularly in Banking, Government and IT).

- Banking and Government organizations differed, being the only sector to use Information Engineering to support SISP.

- Manufacturing, Service, Insurance and several IT organizations did not strongly prefer any methodology, but indicated an absolute lack of use of 7 of the II stated methods. Their choices varied from Business Systems Planning, Critical Success Factors, Strategy Set Transformation to Portfolio Analysis.

- Critical Success Factors, Strategic Planning Grid, Portfolio Analysis and Value Chain Analysis had the strongest preference amongst the largest organizations (including many international ones).

This shows sound evidence of evaluation of alternatives - a key requirement of planning comprehensiveness.

\section{Formalization}

- Overwhelmingly the SISP was formal (55.2\%) rather than informal (27.6\%).

- Those with informal SISP either didn't have an IS mission statement (that the respondent was aware of) or didn't feel the need for one.

- A small number (17.2\%) of organizations in the financial service/IT/IT and legal industry sectors indicated they didn't have a planning process.
- Most organizations had a formal (written) SISP $(82.8 \%$ yes, $17.2 \%$ no), especially those in the IT and Banking sector.

- Whilst not all responded, of those who did respond, the average time spent on SISP per year was 136.17 person days. - There was evidence of formal planning techniques (used by $55.2 \%$, with $17.2 \%$ using a mixture of formal and informal), together with a corporate planning function (93.1\%) and centralized management of SISP processes and outputs (89.6\%).

\section{Focus}

- Organizations generally adopted an integrative approach.

- $89.6 \%$ submitted their final IS strategic plans to top management including the General Manager, Executive, CEO and Managing Director.

- Corporate needs, business value and ROI were the most common considerations in prioritizing decisions regarding IS strategy (96.5\%). Only one organization mentioned creating superior value for customers as a key consideration in prioritizing IS strategy.

- Risks in IS projects were commonly assessed by evaluating cost, loss and impact. This was a formal process for $86.2 \%$ of organizations, with the remainder having ad hoc recognition of risk.

This reported emphasis on integrative approaches was somewhat surprising given the endorsement of competitive advantage as a motivation for SISP. Moreover there was no information about control systems to manage variances in outcomes. These may have been present, but were not commented upon, although there was strong evidence of formal IS strategic plans (by $82.8 \%$ of organizations).

\section{Planning flow}

- Support for this was evident in factors like commitment of senior management and linking IS to organizational goals. - Given successful application of SISP requires such support, results indicate sound awareness of the requirements for an effective SISP process.

- Support for planning is apparent from the long term commitment to SISP (up to 16 years, with an average of 5.9 years).

Our results demonstrated a top-down rather than bottomup approach. This is unsurprising given the consistently formal management style (4I\%) and management's belief in the viability of SISP being seen as a key factor in achieving benefits from SISP $(79.3 \%$ saw this as crucial and $10.3 \%$ as being very important). 


\section{Participation}

- Participants were principally senior corporate management who were not part of IT units (89.7\%), IS steering committees $(79.3 \%)$ and major IS users $(72.4 \%)$ in the SISP process. - Only $24.1 \%$ involved customers as participants in SISP. These organizations were almost entirely international, with 4 operating in the Finance and IT sectors.

- The emphasis in participation concerned involving and gaining the support of top management rather than broad participation, which would have ensured a comprehensive scan of options and opportunities and/or commitment from lower organizational levels.

- Of the people involved with SISP, the mean was 9.72 (range I - 50) and the mean organizational size was 3,12I employees (range 90 - 35,000). This indicated restricted participation.

\section{Consistency}

- With respect to strategic planning cycles, the majority (75.9\%) conducted theirs annually, with a smaller proportion opting for half-yearly cycles (10.3\%). Practices in the remaining organizations varied: one failed to respond (3.4\%), one conducted its planning cycle bi-annually (3.4\%), one constantly (3.4\%), and at the other extreme one (a government agency) conducted its every three years (3.4\%).

- Regarding frequency of SISP committee meetings, common responses were that they met either more frequently than quarterly $(27.6 \%)$ or annually $(27.6 \%)$. Others met quarterly $(20.7 \%)$ or half yearly $(13.8 \%)$, with three failing to respond (I0.3\%) altogether.

- IT and Banking organizations met most frequently: Insurance, Government and Media least frequently.

Regarding the ongoing evaluation of SISP, $58.6 \%$ had a formal review and $37.9 \%$ either had none or an occasional one.This may well relate to their equivocal appraisal of their own SISP outcomes over the last 5 years where $51.7 \%$ saw moderate benefit and $31 \%$ good benefits.

Reflecting on limitations of the study, given the sample was restricted to Australian organizations, this affects generalizability of the results. Further, whilst the sample covered a range of industry sectors and organizational sizes, only 29 organizations were involved. Despite these limitations findings from this research still provide direction for researchers and practitioners.

Given the growth in interest in strategic business/IT alignment as a key component of corporate and enterprise governance, there has been renewed interest in the relevance of SISP. This study updates knowledge about such planning and provides understanding about how SISP can be used in the context of IT governance. Herein, future research could explore the relationship between the frameworks that assist with IT governance like COBIT, Val IT and SISP practices. It could also document what assessment practices have been used successfully to measure earlier SISP as organizations move forward with planning cycles. Studies like this would assist in reducing the risk of project failure and reinforce the role of SISP in the effective overall governance of organizations. Likewise, given the evolving understanding of the strategic relationship between business and IT, practical understanding of managerial approaches to SISP would be beneficial.

\section{Conclusion}

The results from our study demonstrate that comprehensiveness, formalization, focus, flow, participation and consistency were conceptually relevant dimensions through which to evaluate the merit of SISP as practised in our organizations. Herein, focus was more integrative than innovative despite IT and SISP being regarded as a source of competitive advantage. Segars et al. (1998) considered this focus in terms of comprehensiveness and an emphasis on creativity. In our study, the lack of innovative orientation may be attributable to emphasis on the engagement of top management at the expense of the broader organizational community, with outcomes being evaluated in terms of ROI. Equally the lack of an innovative component may in part be linked to a failure to extend the parameters of participation to include people like customers and suppliers. This issue could be further compounded by the lack of external benchmarks for formally evaluating SISP: ISO/IEC 38500:2008 (that addresses corporate governance of IT) and aspects of Cobit (ITGI, 2008) would certainly add a component of independent criteria that could be usefully employed to strengthen and refresh the SISP process.

In summary, as a mechanism by which to plan investment and application of IT to advantage the organization, SISP would appear to have valued relevance in the organizations that we studied. Given the ever increasing recognition of the need for corporate governance of IT, wherein the strategic alignment of business and IT objectives has a primary role, the continued usage of SISP is possibly unsurprising. Our insights gained by using the dimensions as proposed by Segars et al. (1998) to investigate the effectiveness of the SISP process do contribute new knowledge. Firstly, our analysis of the effectiveness of the SISP process showed the continued relevance of Segars et al.'s (1998) dimensions. This approach gave fresh insight regarding how the organizations that we studied could improve their SISP processes.

Secondly, given our organizations' avowed desire for competitive advantage from IT, the lack of their innovative focus

ISSN: 07 I8-2724. (http://www.jotmi.org)

Journal of Technology Management \& Innovation @ Universidad Alberto Hurtado, Facultad de Economía y Negocios. 
would appear to be partly related to the lack of broad participation. Consequently, there may be merit in broadening participation beyond the internal focus suggested by Segars et al. (1998) to capture new insights and innovative opportunities brought about by wider participation (customers and suppliers etc.). In today's dynamic global business environment, just as IT has evolved into a tool to link most facets of business operations from suppliers through the supply chain and business operations to consumers, so should participation in SISP be broadened.

\section{About the Authors}

Carla L. Wilkin is an Associate Professor of Accounting Information Systems in the Department of Accounting and Finance, Faculty of Business and Economics, Monash University, Australia. She holds a BCom (Hons) and a PhD from Deakin University and a Grad Cert Higher Ed from Monash University. Dr Wilkin's major research interests concern: governing IT; system use, appropriation, innovation, diffusion and infusion; measurement of the value of IT; and risk in business processes. She has published in outlets such as European Journal of Information Systems, Decision Support Systems, IT \& People, Electronic Commerce Research, Journal of Information Systems, International Journal of Accounting Information Systems, Electronic Journal of Information Systems Evaluation and Journal of Organizational and End User Computing. Further, she is on the editorial board of the International Journal on IT/Business Alignment and Governance, Journal of Organizational and End User Computing, and International Journal of Accounting Information Systems.

Narciso Cerpa is an Associate Professor in the Computer Science Department, Faculty of Engineering, Universidad de Talca, Chile. He holds a BEng from the Universidad de Santiago, Chile and a MCom and a PhD from the University of New South Wales, Australia. He has held appointments in industry and academia in both Australia and Chile. He was Deputy Vice-Chancellor of Development at the Universidad de Talca (2003-2006). His research interests include software engineering, and electronic commerce. $\mathrm{He}$ is the Editor-inChief of the Journal of Theoretical and Applied Electronic Commerce Research. He is on the Editorial Review Board of the Journal of Global Information Management (JGIM), International Journal of Information Systems in the Service Sector (IIISSS), and the Revista de Universidad y Sociedad del Conocimiento (RUSC). He is also a member of the IFIP Working Groups 6.II (Electronic Commerce - Communication Systems) and 8.4 (E-Business Information Systems: Multi-disciplinary research and practice).

\section{References}

BASU,V., Hartono, E., Lederer,A.L., Sethi V. (2002).The impact of organizational commitment, senior management involvement, and team involvement on strategic information systems planning. Information \& Management, 39(6), 5 I3-524.

BECHOR, T., Neumann, S., Zviran, M., Glezer, C. (20I0). A contingency model for estimating success of strategic information systems planning. Information \& Management, 47(I), 17-29.

BERNROIDER, E.W.N. (2008). IT governance for enterprise resource planning supported by the DeLone-McLean model of information systems success. Information \& Management, 45(5), 257-269.

BROWN, C.V. (1999). Horizontal mechanisms under differing IS organization contexts. MIS Quarterly, 23(3), 42 I-454.

CERPA, N.,Verner, J. (1998). Case study:The effect of IS maturity on information systems strategic planning. Information \& Management, 34(4), 199-208.

CHURCHILL, G.A. (1979). A paradigm for developing better measures of marketing constructs. Journal of Marketing Research, I6(I), 64-73.

COHEN, J. (2008). Context determinants and performance implications of information systems strategy planning within South African firms. Information \& Management, 45(8), 547555.

COUTAZ, J., Crowley,J.L., Dobson, S., Garlan, D. (2005). Context is the key. Communications of the ACM, 48(3), 49-53.

EISENHARDT, K.M. (2002). Has strategy changed? MIT Sloan Management Review, 43(2), 88-91.

FREDRICKSON, J.W., Mitchell,T.R. ( 1984$)$. Strategic decision processes: Comprehensiveness and performance in an industry with an unstable environment. Academy of Management Journal, 27(2), 399-423

GALLIERS, R.D. (1991). Strategic information systems planning: Myths, reality and guidelines for successful implementation. European Journal of Information Systems, I, 55-64.

GROVER, V., Segars, A.H. (2005). An empirical evaluation of stages of strategic information systems planning: Patterns of process design and effectiveness. Information \& Management, 42(5), 76I-779.

HOLLEY, L.M., Duffner, D., Reed, B.J. (2004). Strategic information systems planning in US county governments:Will the

ISSN: 07 I8-2724. (http://www.jotmi.org)

Journal of Technology Management \& Innovation (C) Universidad Alberto Hurtado, Facultad de Economía y Negocios. 
real SISP model please stand up?, Public Performance and Management Review, 27(3), 102-I27.

ISO/IEC 38500:2008. Corporate governance of information technology. International Standards Organization. Available at http://20000.standardsdirect.org/

ITGI. (2009) An executive view of IT governance. Available at: http://www.itgi.org/AMTemplate.cfm?SectionDeliverables \&Template/ContentManagement.Accessed September 2009.

ITGI, (Val IT). (2008). Enterprise value: Governance of IT investments. Getting started with value management. Available at www.itgi.org. Accessed September 2009.

KIM W.C., Mauborgne, R.. (1999). Strategy, value innovation, and the knowledge economy. Sloan Management Review 40 (3), $4 \mathrm{I}-54$.

KING, W.R. (1988). How effective is your information systems planning? Long Range Planning, 2I (5), I03-I I 2.

KING,W.R. (1978). Strategic planning for management information systems. MIS Quarterly, 2(I), 27-39.

KUKALIS, S. (1991). Determinants of strategic planning systems in large organizations: A contingency approach. Journal of Management Studies, 28(2), I43-I60.

LEDERER, A.L., Sethi, V. (1996). Key prescriptions for strategic information systems planning. Journal of Management Information Systems, I 3(I), 35-62.

LEDERER,A.L., Sethi,V. (1988).The implementation of strategic information systems planning methodologies. MIS Quarterly, I2(3), 445-46I.

MCKERSIE, R.B.,Walton, R.E. (199I). Organizational change. in The Corporation of the 1990s. ed. M.S. Scott Morton. Oxford University Press. New York.

PEAK, D.C., Guynes, S., Kroon, V. (2005). Information technology alignment planning - A case study. Information \& Management, 42(4), 619-633.

PETER, J.P. (I98I). Construct validity:A review of basic issues and marketing practices. Journal of Marketing, 18(2), I33145.

PORTER, M.E., Millar,V.E. (1985). How information gives you competitive advantage. Harvard Business Review, 63(4), I49160.
REMKUMAR, G., King,W.R. (1992). An empirical assessment of information systems planning and the role of information systems in organizations. Journal of Management Information Systems, 9(2), 99-125.

PYBURN, P.J. (1983). Linking the MIS Plan with corporate strategy: An exploratory study. MIS Quarterly, 7(2), I- I 4.

READ,T.J. (2004). Discussion of director responsibility for IT governance. International Journal of Accounting Information Systems, 5(2), 105-107.

REICH, B.H., Benbasat, I. (2000). Factors that influence the social dimension of alignment between business and information technology objectives. MIS Quarterly, 24(I), 8I-II3.

SCHWARZ,A., Hirschheim, R. (2003).An extended platform logic perspective of IT governance: Managing perceptions and activities of IT. Journal of Strategic Information Systems, 12(2), I29-166.

SEGARS, A.H., Grover, V., Teng, J.T.C. (1998). Strategic information systems planning: Planning system dimensions, internal coalignment, and implications for planning effectiveness. Decisions Sciences, 29(2), 303-345.

(THE) STANDISH Group. (2004). Third Quarter Research Report: Chaos Demographics. Available at http://standishgroup.com/quarterly_reports/

TALLON, P. (2007/2008). A process-oriented perspective on the alignment of information technology and business strategy. Journal of Management Information Systems, 24(3), 227-268.

VENKATARAMAN, N., Grant, J.H. (1986). Construct measurement in organizational strategy research: $\mathrm{A}$ critique and proposal.Academy of Management Review, I I (I), 7I-87.

WATTERS, D. (2004). IBM strategy and change survey of fortune $1000 \mathrm{ClOs}$. As presented to SHARE in New York by Doug Watters 17 August 2004.

WEILL, P., Ross, J. (2005). A matrixed approach to designing IT governance. MIT Sloan Management Review, 46(2), 26-34.

WILKIN, C.L., Chenhall, R.H. (2010).A review of IT governance:A taxonomy to inform accounting information systems. Journal of Information Systems, 24(2), 107-I 46. 
J.Technol. Manag. Innov. 2012,Volume 7, Issue 2

ISSN: 07I8-2724. (http://www.jotmi.org)

Journal of Technology Management \& Innovation @ Universidad Alberto Hurtado, Facultad de Economía y Negocios. 